\title{
Dynamics of antigenemia and transmission intensity of Wuchereria bancrofti following cessation of mass drug administration in a formerly highly endemic region of Mali
}

Yaya I. Coulibaly ${ }^{1,4^{*}}$, Siaka Y. Coulibaly ${ }^{1}$, Housseini Dolo ${ }^{1}$, Siaka Konate ${ }^{1}$, Abdallah A. Diallo ${ }^{1}$, Salif S. Doumbia ${ }^{1}$, Lamine Soumaoro ${ }^{1}$, Michel E. Coulibaly ${ }^{1}$, Ilo Dicko ${ }^{1}$, Moussa B. Sangare ${ }^{1}$, Benoit Dembele ${ }^{1}$, Modibo Sangare ${ }^{1}$, Massitan Dembele ${ }^{2}$, Yeya T. Touré ${ }^{3}$, Louise Kelly-Hope ${ }^{4}$, Katja Polman $^{5}$, Dominique Kyelem ${ }^{\wedge}$, Sekou F. Traore ${ }^{1}$, Moses Bockarie ${ }^{7}$ Amy D. Klion ${ }^{8}$ and Thomas B. Nutman ${ }^{8}$

\begin{abstract}
Background: After seven annual rounds of mass drug administration (MDA) in six Malian villages highly endemic for Wuchereria bancrofti (overall prevalence rate of $42.7 \%$ ), treatment was discontinued in 2008. Surveillance was performed over the ensuing 5 years to detect recrudescence.

Methods: Circulating filarial antigen (CFA) was measured using immunochromatographic card tests (ICT) and Og4C3 ELISA in 6-7 year-olds. Antibody to the W. bancrofti infective larval stage (L3) antigen, Wb123, was tested in the same population in 2012. Microfilaraemia was assessed in ICT-positive subjects. Anopheles gambiae complex specimens were collected monthly using human landing catch (HLC) and pyrethrum spray catch (PSC). Anopheles gambiae complex infection with $W$. bancrofti was determined by dissection and reverse transcriptase polymerase chain reaction (RT-PCR) of mosquito pools.
\end{abstract}

Results: Annual CFA prevalence rates using ICT in children increased over time from 0\% (0/289) in 2009 to 2. $7 \%(8 / 301)$ in 2011, 3.9\% (11/285) in 2012 and 4.5\% (14/309) in 2013 (trend $x^{2}=11.85, d f=3, P=0.0006$ ). Wb123 antibody positivity rates in 2013 were similar to the CFA prevalence by ELISA (5/285). Although two W. bancrofti-infected Anopheles were observed by dissection among 12,951 mosquitoes collected by HLC, none had L3 larvae when tested by L3-specific RT-PCR. No positive pools were detected among the mosquitoes collected by pyrethrum spray catch. Whereas ICT in 6-7 year-olds was the major surveillance tool, ICT positivity was also assessed in older children and adults (8-65 years old). CFA prevalence decreased in this group from 4.9\% (39/800) to 3.5\% (28/795) and 2.8\% (50/1,812) in 2009, 2011 and 2012, respectively (trend $\left.X^{2}=7.361, d f=2, P=0.0067\right)$. Some ICT-positive individuals were microfilaraemic in 2009 [2.6\% (1/39)] and 2011 [8.3\% (3/36)], but none were positive in 2012 or 2013.

(Continued on next page)

\footnotetext{
* Correspondence: yicoulibaly@icermali.org

'Deceased

${ }^{1}$ Filariasis Unit, International Center of Excellence in Research, Faculty of

Medicine and Odontostomatology, Point G, Bamako, Mali

${ }^{4}$ Filarial Program Support Unit, Liverpool School of Tropical Medicine,

Liverpool, UK

Full list of author information is available at the end of the article
} 
(Continued from previous page)

Conclusion: Although ICT rates in children increased over the 5-year surveillance period, the decrease in ICT prevalence in the older group suggests a reduction in transmission intensity. This was consistent with the failure to detect infective mosquitoes or microfilaraemia. The threshold of ICT positivity in children may need to be re-assessed and other adjunct surveillance tools considered.

Keywords: Wuchereria bancrofti, Transmission assessment survey, Anopheles gambiae complex, Mass drug administration, Post-MDA surveillance

\section{Background}

Lymphatic filariasis (LF) is a public health problem in 71 countries and is associated with marked morbidity and disability [1]. To eliminate LF by 2020, the Global Program to Eliminate LF (GPELF) adopted strategies based on two pillars: annual mass drug administration (MDA) to all eligible residents of the endemic communities and morbidity management [2]. MDA is aimed at interrupting LF transmission through clearing of peripheral blood microfilariae that prevent human-to-human vectorborne transmission [2].

As Bancroftian filariasis was found to be endemic in all eight administrative districts of Mali, ranging from $1 \%$ in Timbuktu (northern part of Mali) to $>18 \%$ in Sikasso (southern part of the country) [3], annual MDA using ivermectin and albendazole was initiated sequentially starting from the most highly endemic district in the country [3]. Sentinel sites were established in Sikasso as part of a multicountry initiative to assess LF transmission during and after stopping MDA. The baseline data and the impact of six rounds of MDA on human infection and potential transmission in this sentinel site have been previously reported [4].

The current study reports data collected to assess transmission after MDA was stopped in 2007 (after seven rounds of MDA). Although this study was initiated prior to the formal WHO recommendations for transmission assessment surveys (TAS), which require demonstration of an infection rate of $<1 \%$ in $>400$ children aged 6-7 years using the immunochromatographic card test (ICT) to document interruption of transmission [5], a similar approach was taken using ICT testing of children aged $6-7$ years. ICT testing of a cohort of children $\geq 8$ years old and adults and entomological assessment of LF transmission were performed. Finally, the use of several additional methods (Og4C3 ELISA; Polymerase Chain Reaction (PCR) targeting Wuchereria bancrofti DNA; and W. bancrofti infective larval stage specific antigen Wb123-based IgG4 immunoassays) to assess transmission interruption in this previously highly LF-endemic region (Sikasso) of Mali was explored. Our data support an integrated approach to surveillance.

\section{Methods \\ Study sites}

The study area comprised six villages in Sikasso district: Gondaga, Dozanso, Missasso, N'torla, Niatanso and Zanadougou. These villages are located in the rural commune of Kolokoba that is located $332 \mathrm{~km}$ southeast of Bamako the capital city. Wuchereria bancrofti infection prevalence as assessed by the detection of CFA using ICT prior to MDA was 46\% [4]. This area is also endemic for Mansonella perstans, but not Onchocerca volvulus infection. Based on 2012 census data, the total population of the 6 villages was 5044 . The study villages had undergone 7 annual rounds of MDA prior to its cessation in 2008, at which time the CFA prevalence had decreased to 0/760 children tested and the Anopheles gambiae complex mosquitoes showed an infection rate of $0.04 \%$ and an infectivity rate of $0.02 \%$ that were felt to be incompatible with active LF transmission [6]. There was a mean programmatic coverage rate based on the total population of $75.6 \%$ that varied from 67 to $78 \%$ [6]. A year after cessation of MDA (in 2009), no infected 6-7 year-old children were found among the 120 tested in the six villages.

\section{Study design}

As post-MDA surveillance, a yearly cross-sectional parasitological assessment of all children 6-7 years of age and all eligible older volunteers aged 8 years and above was performed in July from 2009 to 2012. In addition, a monthly entomological assessment of LF transmission (from July to December) was conducted in the six study villages in 2009, 2011 and 2013. In 2013, only children aged 6-7 years were tested with the ICT, along with a thick smear from night blood. Infective stage $W$. bancrofti larvae (L3) were assessed in mosquitoes using an L3specific reverse transcriptase PCR (RT-PCR) technique as previously described [7]. The study design is illustrated in Fig. 1. EVAL refers to the ensemble of surveillance testing performed in any given year.

\section{Parasitological and serological assessments}

Infection status was assessed using the ICT card test for the detection of circulating W. bancrofti antigen (Allere, Portland, ME, USA). Dried blood spots were collected for additional laboratory analyses. Microfilaraemia was 


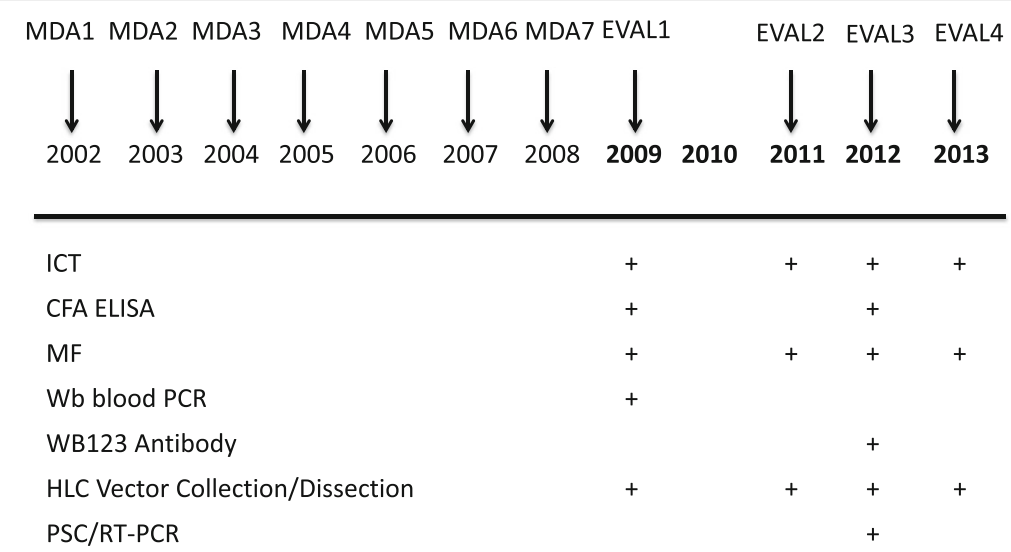

Fig. 1 Time line of treatment, EVAL, and monitoring. The years in which MDA and EVAL surveys were performed are shown by the arrows and times at which monitoring tools in support of EVAL are shown by the + sign

assessed by finger prick at night (between 22:00 and 02:00 h) among ICT-positive volunteers using a calibrated thick smear. Yearly parasitological studies were conducted in July, at the beginning of the transmission period, except in 2009 when, for logistical reasons, this assessment was performed in October. Because of the concern of potential transmission, additional diagnostic tests were performed on eluted blood spots from the 6-7 year-old children in 2012, namely the Og4C3 ELISA (Tropbio Townsville, Australia) and ELISA testing for antibodies to Wb123 as previously described [8].

\section{Entomological assessment}

Each month, a 12-day entomological survey was conducted in the six villages to assess the village wide $W$. bancrofti transmission patterns during the LF transmission period in Mali from July to December [4]. Two human landing catch (HLC) sessions were organized per month and per village. Two collectors worked inside each of four collection rooms per session.

Because An. gambiae is endophilic, collections were performed indoors to maximize yield. A total of 72 collection rounds were undertaken with the HLC. The collection was done from 18:00 to $06: 00 \mathrm{~h}$, and for ethical reasons, the collectors were replaced at midnight at each collection site. All An. gambiae and An. funestus complexes collected were freshly dissected for parity status based on techniques previously described $[9,10]$ and for infection (any larval stage) and infectivity (L3 stage) status by individual mosquito dissection as previously described [11].

In 2012, the PSC (Pyrethrum Spray Catch) was used to collect mosquito vectors in addition to the HLC using Premium $^{\circ}$, a pyrethrinoid-based insecticide, in 30 randomly selected rooms per village in each of the six collection months. During each of the 36 PSC collection rounds, the number of persons sleeping in each visited room was recorded on the mosquito collection sheet. The collected mosquitoes during the PSC were pooled ( 1 to 20 mosquitoes) in the field and stored in tubes containing RNA later and sent to Smith College for $W$. bancrofti RNA detection by RT-PCR as previously described [7].

For PSC, the monthly biting rate was determined by dividing the number of fed and half-gravid female Anopheles collected in a room by the number of sleepers in the room the night before the collection multiplied by 30 [12]. The annual biting rate (ABR) was the sum of all the monthly biting rates calculated over the year [12] From HLC-collected Anopheles, the parameters were determined as previously reported $[12,13]$.

\section{Sampling}

The present study predated the official WHO guidelines for TAS [5]. Because the evaluation unit was small $(<300$ children aged 6-7 years), all of the available eligible children were screened.

\section{Data analysis}

The collected data were entered using Microsoft Access 2007 and analysed using Graph Pad prism version 5 and Statistical Package for Social Sciences (SPSS) version 20. To compare the infection prevalences between villages or mosquito species, we used the Pearson $\chi^{2}$ or the Fisher's exact test, if necessary. The trend $\chi^{2}$ was used to test the statistical significance of any frequency or proportion's trend over time.

\section{Results}

\section{Study demographics}

We assessed 289 children aged 6-7 years in 2009, 301 in 2011, 285 in 2012 and 309 in 2013. Concomitantly, available older children and adults were assessed in $2009(n=800), 2011 \quad(n=795)$, and $2012(n=1812)$ 
(Tables 1 and 2). In 2013, testing of older children and adults was restricted to those who were positive by ICT in $2012(n=50)$. Although the sizes of the six study villages differed, the study populations within the villages were quite well balanced in terms of gender within both the 6 to 7 year-old children and the $\geq 8$ year-olds throughout the study period (Table 2).

\section{CFA and Wb123 antibody prevalence assessment over the} surveillance period

The CFA prevalence in 6-7 year-old children increased significantly over the surveillance period, from $0 \%(0 /$ $289)$ in 2009 to $2.7 \%(8 / 301)$ in 2011 and $4.5 \%(14 / 309)$ in 2013 (trend $\chi^{2}=12.80, d f=3, P=0.0003$ ) (Table 3). In contrast, there was a significant decrease in CFA positivity over the study period in the $\geq 8$ year-olds, from $4.9 \%$ $(39 / 800)$ in 2009 to $3.5 \%(28 / 795)$ in 2011 , to $2.8 \%(50 /$ 1,812 ) in 2012 (trend $\chi^{2}=697.8, d f=2, \quad P=0.0001$ ). Whereas none of the ICT-positive 6-7 year-olds had detectable microfilaraemia, 1 of 39 (2.6\%) individuals in the older group was microfilaraemic in 2009 , and $3 / 36$ (8.3\%) were microfilaraemic in 2011. In 2012, none of the 50 ICT-positive older subjects was microfilaraemic (Table 3). Forty-four of the previously ICT-positive older subjects, as well as 6 of the 6-7 year-olds who were ICT-positive and 8 years old at the time of the 2013 survey, were reassessed in 2013. None of the 28 subjects who remained ICT-positive in 2013 had detectable microfilaraemia (data not shown). Positivity rates for both the Og4C3 ELISA for CFA and testing for antibodies to the W. bancrofti-specific antigen, Wb 123, were similar to the results obtained using the ICT tests $\left(\chi^{2}=3.52, d f=2, P=0.173\right)$.

\section{Entomological assessment}

The number of mosquitoes collected using the HLC over the study period is detailed in Table 4. The highest ABR using the HLC was 374 bites per person in 2012 and the lowest was in 2011 with 155 bites per person. Among the dissected mosquitoes, the parity rates were significantly different between the 3 yearly entomological surveys with $84 \%(3,675 / 4,380)$ in $2009,84 \%(2,406 /$
$2,853)$ in 2011 and $88 \%(5,032 / 5,718)$ in $2012\left(\chi^{2}=\right.$ 40.76, $\left.d f=2, P<10^{-4}\right)$. In 2009 , two $(0.05 \%)$ filariainfected Anopheles females were detected (Table 4) without any infective larval stage recovered. In 2011 and 2012, no W. bancrofti larvae were found in the dissected mosquitoes (data not shown).

With the PSC method during the 6 months of collection in 2012, 1907 mosquitoes were collected and the ABR was 100 bites per person per year. The number of mosquitoes collected with the PSC technique was 3.75 times less than that collected with the HLC in 2012. Moreover, both the infection and infectivity of the PSCcollected mosquitoes were 0 (Table 4). Of note, $A n$. gambiae complex was the most frequent vector comprising more than $99 \%$ of the active vector fauna each year as compared to An. funestus complex (data not shown).

We observed the highest vector density (12 mosquitoes per person per night) in 2012 with 7165 mosquitoes collected by 576 collectors. This density was 2.4 times higher than that in 2011 (2962 mosquitoes) and 1.6 times more than that in 2009 (4448 mosquitoes). Of the 2962 and 7165 mosquitoes collected in 2011 and 2012, respectively, the frequencies of $A n$. pharaoensis varied from $1.31 \%$ in 2011 to $0.32 \%$ in 2012 while the frequencies of An. rufipes varied from $0.30 \%$ in 2011 to $0.01 \%$ in 2012. These species were very rare during the previous collection years in this area and were never found to be infected with W. bancrofti (Table 4).

\section{Discussion}

The current study investigated the LF transmission patterns following cessation of MDA during the surveillance period from 2009 to 2013 in six neighbouring previously highly LF endemic villages in the Sikasso region in Mali. In 2008, after seven rounds of MDA, the W. bancrofti microfilaraemia and ICT positivity in children (6-7 years) was reduced to 0\%. By 2011 and 2012, the prevalence of ICT-positivity in 6-7 year-old children showed an increase, although microfilaraemia was not detected. Despite a steady increase in CFA prevalence in 6-7 year-old children, there was a marked decrease in CFA prevalence rates over the same 5 year period among those $\geq 8$ years of age

Table 1 Sampling according to different activities per year

\begin{tabular}{|c|c|c|c|c|c|c|}
\hline \multirow[b]{2}{*}{ Year } & \multicolumn{3}{|c|}{ Study human sample } & \multicolumn{3}{|l|}{ Mosquito collection } \\
\hline & Total population & $6-7$ years old & $\geq 8$ years & Number collected & Technique used & Number of collection rounds \\
\hline 2009 & 4,431 & 289 & 800 & 4,448 & $\mathrm{HLC}$ & 72 \\
\hline $2011^{a}$ & 4,761 & 301 & 795 & 2,962 & HLC & 72 \\
\hline 2012 & 5,044 & 285 & 1,812 & $7,168 / 1,907$ & HLC/PSC & $72 / 36^{b}$ \\
\hline $2013^{c}$ & 5,225 & 309 & 50 & nd & nd & nd \\
\hline
\end{tabular}

Abbreviation: $n d$ not done

${ }^{a}$ In 2011, a random sample of 92 subjects from the 6 villages was tested with Wb123 ELISA

${ }^{b}$ In 2012, the six villages were visited once a month from July to December (collection in 30 rooms per visit per village)

'In 2013 the 50 subjects $\geq 8$ years tested were the ones found positive using ICT in 2012 
Table 2 Characteristics of the study population per village throughout the surveillance period in the 6 study villages of the Sikasso district

\begin{tabular}{|c|c|c|c|c|c|c|}
\hline \multirow[t]{2}{*}{ Village } & \multicolumn{2}{|l|}{$6-7$ years } & \multicolumn{3}{|c|}{8 years and above } & \multirow[t]{2}{*}{ Overal } \\
\hline & $\overline{M / F}$ & $\overline{\text { Total }}$ & $\overline{M / F}$ & Median age (Range) & $\overline{\text { Total }}$ & \\
\hline \multicolumn{7}{|l|}{ Survey 1 in 2009} \\
\hline Dozanso & $20 / 29$ & 49 & $60 / 73$ & $34(12-79)$ & 133 & 182 \\
\hline Missasso & $26 / 20$ & 46 & $64 / 94$ & $40(15-76)$ & 158 & 204 \\
\hline Gondaga & $22 / 21$ & 43 & $55 / 64$ & $33(12-75)$ & 119 & 162 \\
\hline Niatanso & $30 / 24$ & 54 & $91 / 106$ & $31(12-69)$ & 197 & 251 \\
\hline NTorla & $23 / 16$ & 39 & $50 / 49$ & $37(12-72)$ & 99 & 138 \\
\hline Zanadougou & $28 / 30$ & 58 & $31 / 63$ & $37.5(13-77)$ & 94 & 152 \\
\hline Total & $149 / 140$ & 289 & $351 / 449$ & $35(12-79)$ & 800 & 1,089 \\
\hline \multicolumn{7}{|l|}{ Survey 2 in 2011} \\
\hline Dozanso & $21 / 17$ & 38 & $42 / 71$ & $32(15-82)$ & 113 & 151 \\
\hline Missasso & $22 / 31$ & 53 & $51 / 99$ & $35(15-86)$ & 150 & 203 \\
\hline Gondaga & $21 / 17$ & 38 & $58 / 73$ & $29(15-84)$ & 131 & 169 \\
\hline Niatanso & $25 / 29$ & 54 & $73 / 60$ & $31(15-82)$ & 133 & 187 \\
\hline NTorla & $35 / 26$ & 61 & $53 / 80$ & $31(15-88)$ & 133 & 194 \\
\hline Zanadougou & $26 / 31$ & 57 & $49 / 86$ & $31(15-89)$ & 135 & 192 \\
\hline Total & $150 / 151$ & 301 & $326 / 469$ & 38 (15-89) & 795 & 1,096 \\
\hline \multicolumn{7}{|l|}{ Survey 3 in 2012} \\
\hline Dozanso & 20/16 & 36 & $95 / 137$ & $32(15-82)$ & 232 & 268 \\
\hline Missasso & $21 / 27$ & 48 & 101/171 & $33(15-79)$ & 272 & 320 \\
\hline Gondaga & $27 / 21$ & 48 & 100/177 & $28(15-85)$ & 277 & 325 \\
\hline Niatanso & $26 / 25$ & 51 & $134 / 182$ & $28(15-83)$ & 316 & 367 \\
\hline NTorla & $22 / 15$ & 37 & $127 / 208$ & 30 (15-89) & 335 & 372 \\
\hline Zanadougou & $34 / 31$ & 65 & $137 / 243$ & $30(15-80)$ & 380 & 445 \\
\hline Total & $150 / 135$ & 285 & $694 / 1,118$ & $30(15-89)$ & 1,812 & 2,097 \\
\hline \multicolumn{7}{|l|}{ Survey 4 in 2013} \\
\hline Dozanso & $24 / 24$ & 48 & $8 / 15$ & $41(8-75)$ & 23 & 73 \\
\hline Missasso & $26 / 21$ & 47 & $1 / 4$ & $38(31-68)$ & 5 & 52 \\
\hline Gondaga & $30 / 25$ & 55 & $0 / 5$ & $28(8-58)$ & 5 & 60 \\
\hline Niatanso & $32 / 23$ & 55 & $1 / 3$ & $25.5(8-63)$ & 4 & 60 \\
\hline NTorla & $18 / 24$ & 42 & $1 / 6$ & $46(24-66)$ & 7 & 49 \\
\hline Zanadougou & $31 / 31$ & 62 & $4 / 2$ & $29(8-58)$ & 6 & 68 \\
\hline Total & $161 / 148$ & 309 & $15 / 35$ & $38(8-75)$ & 50 & 359 \\
\hline
\end{tabular}

Abbreviation: $M / F$ male/female

(trend $X^{2}=7.361, d f=3, P=0.0067$ ). This decrease is consistent with attrition over time of established worms. Despite the increasing CFA prevalence in children, our data are most consistent with interruption of LF transmission based on the absence of detectable microfilaraemia, the lack of infective Anopheles, and the decreased CFA prevalence in the older age group. Nonetheless, close monitoring in areas of previously high transmission is necessary to detect early resurgence of transmission and to generate data that may guide and improve the LF elimination process.
When prevalence was estimated using different tools (Og4C3 ELISA and Wb123 immunoassays) at a single time point (2012), ICT consistently gave a higher prevalence rate compared to the two other tests, although the differences in prevalence were not statistically significant. Higher prevalences using ICT compared to Og4C3 ELISA was also observed in Togo during a school-based TAS conducted 3 years after stopping MDA [14], although the reasons for this are unclear. Loa loa microfilaraemia has been shown to be associated with ICT-positivity at both 
Table 3 Circulating filarial antigen (CFA) and microfilaraemia prevalence rates within 6-7 year-old children and those of 8 years and above from 2009 to 2013

\begin{tabular}{|c|c|c|c|c|c|}
\hline & & Survey 1 (2009) & Survey 2 (2011) & Survey $3(2012)^{a}$ & Survey 4 (2013) \\
\hline \multirow[t]{3}{*}{ Sample size and target } & Targeted sample size & 1,107 & 1,107 & 2,530 & 372 \\
\hline & Total population & 4,431 & 4,761 & 5,044 & 5,225 \\
\hline & Number tested $(n)$ & 1,089 & 1,096 & 2,097 & 359 \\
\hline \multirow[t]{4}{*}{$\mathrm{ICT}$} & $\geq 8$ years $\%$ Positive $(n / N)$ & $4.9 \%(39 / 800)$ & $3.5 \%(28 / 795)$ & $2.8 \%(50 / 1,812)$ & \\
\hline & {$[95 \% \mathrm{Cl}]$} & {$[3.53-6.67]$} & {$[2.40-5.12]$} & {$[2.08-3.65]$} & - \\
\hline & $6-7$ years \% Positive $(n / N)$ & $0 \%(0 / 289)$ & $2.7 \%(8 / 301)$ & $3.9 \%(11 / 285)$ & $4.5 \%(14 / 309)$ \\
\hline & {$[95 \% \mathrm{Cl}]$} & {$[0.00-1.64]$} & {$[1.24-5.37]$} & {$[2.04-7.00]$} & {$[2.60-7.66]$} \\
\hline \multirow[t]{4}{*}{ Mf } & $\geq 8$ years $\%$ Positive $(n / N)^{b}$ & $2.6 \%(1 / 39)$ & $10.7 \%(3 / 28)$ & $0 \%(0 / 50)$ & \\
\hline & {$[95 \% \mathrm{Cl}]$} & {$[0.06-13.48]$} & {$[2.81-29.37]$} & {$[0.00-8.89]$} & - \\
\hline & $6-7$ years \% Positive $(n / N)^{b}$ & 0 & $0 \%(0 / 8)$ & $0 \%(0 / 11)$ & $0 \%(0 / 14)$ \\
\hline & {$[95 \% \mathrm{Cl}]$} & & {$[0.00-40.23]$} & {$[0.00-32.15]$} & {$[0.00-26.76]$} \\
\hline \multirow[t]{4}{*}{ PCR } & $\geq 8$ years $\%$ Positive $(n / M)$ & $5.13 \%(2 / 39)$ & $\mathrm{np}$ & $\mathrm{np}$ & $\mathrm{np}$ \\
\hline & {$[95 \% \mathrm{Cl}]$} & [0.89-18.63] & & & \\
\hline & $6-7$ years \% Positive $(n / N)$ & 0 & $\mathrm{np}$ & $\mathrm{np}$ & $\mathrm{np}$ \\
\hline & {$[95 \% \mathrm{Cl}]$} & & & & \\
\hline \multirow[t]{4}{*}{ Wb123 } & $\geq 8$ years $\%$ Positive $(n / M)$ & $\mathrm{np}$ & $\mathrm{np}$ & $4.7 \%(2 / 43)$ & nd \\
\hline & {$[95 \% \mathrm{Cl}]$} & & & {$[0.81-17.06]$} & \\
\hline & $6-7$ years \% Positive $(n / N)$ & $\mathrm{np}$ & $\mathrm{np}$ & $1.8 \%(5 / 285)$ & nd \\
\hline & {$[95 \% \mathrm{Cl}]$} & & & {$[0.65-4.27]$} & \\
\hline \multirow[t]{4}{*}{$\mathrm{Og} 4 \mathrm{C3}$} & $\geq 8$ years ICT \% Positive $(n / N)$ & $\mathrm{np}$ & $\mathrm{np}$ & $4 \%(2 / 50)$ & $\mathrm{np}$ \\
\hline & {$[95 \% \mathrm{Cl}]$} & & & {$[0.70-14.86]$} & \\
\hline & $6-7$ years \% Positive $(n / N)$ & $\mathrm{np}$ & $\mathrm{np}$ & $1.8 \%(5 / 285)$ & $\mathrm{np}$ \\
\hline & {$[95 \% \mathrm{Cl}]$} & & & {$[0.65-4.27]$} & \\
\hline
\end{tabular}

Abbreviations: ELISA enzyme-linked immuno-sorbent assay, ICT immunochromatographic card test, ICT+ ICT positive, Mf microfilaraemia, $n$ number positive, $N$ number examined, $n d$ not done, $n p$ not planned, $P C R$ polymerase chain reaction, $W b 123$ filarial antibody test ${ }^{a}$ In 2012, the ELISA test was done on all the children and the 50 ICT positive adults

${ }^{b}$ Only the ICT positive subjects were tested for Mf

the community and individual levels $[15,16]$; however, the same studies showed no association between ICTpositivity and the prevalence of $M$. perstans, the only other filarial parasite endemic in the study area [17].

Re-emergence of infection after just a few years of surveillance has been reported in Nigeria in some but not in all districts [18]. In India after 10 years following MDA implementation, new infection among children was also reported [19]. Using 6-7 year-old children as the sentinel population makes sense in the Malian context because this group remains in the villages, whereas many adults travel from place to place because of seasonal migration for agriculture and may acquire infection in areas that have not yet started MDA [20].

The approach to post-MDA surveillance is still being perfected. Antibody testing (e.g. Wb123) has been proposed as a potential better tool than antigen testing for the early identification of on-going transmission, as antibody positivity typically occurs months prior to positivity in adult antigen-based circulating antigen testing [21-23]. As there was good concordance between Wb123 prevalence and that of the CFA testing in the children (see Table 1) and with both tests now being point of care (POC) $[8,24]$, it is possible that the $\mathrm{Wb} 123$ rapid diagnostic test may be considered as a major surveillance tool in the near future.

Although screening of vector populations for the presence of infective larvae has been one of the 2 pillars of assessing transmission interruption in onchocerciasis $[25,26]$, its widespread use in LF has not taken hold to date. However, using both standard (dissection) and molecular techniques on both HLC and PSC collected mosquitoes $(n=9072)$ only a few positives were found (and only just after the cessation of MDA). This is probably due to the drastic reduction of microfilaraemia prevalence after the seven consecutive MDA treatments and to the relatively low number of mosquitoes collected and the low sensitivity of the dissection [7]. Since RTPCR, a more sensitive method to detect infective stage L3 larvae in the vector, is available [7], screening of 
Table 4 Annual variation of mosquito densities and biting rates over the surveillance period from 2009 to 2012

\begin{tabular}{|c|c|c|c|c|c|c|c|}
\hline Collection method & Years & Species & No. of mosquitoes collected & $\begin{array}{l}\text { No. of mosquitoes dissected } \\
\text { Frequency }[95 \% \mathrm{Cl}]\end{array}$ & $A B R$ & $\begin{array}{l}\text { Parity } \\
\text { Frequency [95\% Cl] }\end{array}$ & $\begin{array}{l}\text { Infection } \\
\text { Frequency [95\% Cl] }\end{array}$ \\
\hline \multirow[t]{22}{*}{$\overline{\mathrm{HLC}}$} & 2009 & GA & 4,443 & 4,375 & 232 & 3,671 & 2 \\
\hline & & & & $98.47[98.05-98.8]$ & & 83.9 [82.78-84.98] & $0.05[0.01-0.18]$ \\
\hline & & FU & 5 & 5 & 0 & 4 & 0 \\
\hline & & & & 100 [46.29-100] & & 80 [29.88-98.94] & \\
\hline & & $\mathrm{PH}$ & 0 & 0 & 0 & 0 & 0 \\
\hline & & $\mathrm{RU}$ & 0 & 0 & 0 & 0 & 0 \\
\hline & 2011 & GA & 2,911 & 2,803 & 152 & 2,364 & 0 \\
\hline & & & & 96.29 [95.52-96.93] & & 84.34 [82.92-85.65] & \\
\hline & & FU & 3 & 3 & 0 & 3 & 0 \\
\hline & & & & $100[31.00-100]$ & & 100 [31.00-100] & \\
\hline & & $\mathrm{PH}$ & 39 & 38 & 2 & 30 & 0 \\
\hline & & & & 97.44 [84.92-99.87] & & $78.95[62.22-89.86]$ & \\
\hline & & $\mathrm{RU}$ & 9 & 9 & 1 & 9 & 0 \\
\hline & & & & $100[62.88-100]$ & & $100[62.88-100]$ & \\
\hline & 2012 & GA & 7,138 & 5,691 & 368 & 5,006 & 0 \\
\hline & & & & 79.82 [78.86-80.74] & & 88.9 [88.05-89.70] & \\
\hline & & FU & 3 & 3 & 0 & 3 & 0 \\
\hline & & & & 100 [31.00-100] & & 100 [31.00-100] & \\
\hline & & $\mathrm{PH}$ & 23 & 23 & 1 & 22 & 0 \\
\hline & & & & 100 [77.08-100] & & 94.1 [69.23-99.69] & \\
\hline & & $R U$ & 1 & 1 & 0 & 1 & 0 \\
\hline & & & & $100[5.46-100]$ & & $100[5.46-100]$ & \\
\hline \multirow[t]{3}{*}{ PSC } & 2009 & & nd & nd & nd & nd & nd \\
\hline & 2011 & & nd & nd & nd & nd & nd \\
\hline & 2012 & An. spp. & 1,907 & $115^{\mathrm{a}}$ & $12^{\mathrm{b}}$ & nd & 0 \\
\hline
\end{tabular}

Abbreviations: An. spp. Anopheles species, HBR human biting rate, HLC human landing catch, FU Anopheles funestus, GA Anopheles gambiae, PH Anopheles pharaoensis, PSC Pyrethrum spray catch, RU Anopheles rufipes, nd not done

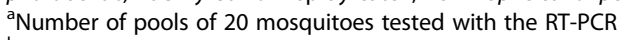

${ }^{\mathrm{b}}$ The number of half gravid and blood fed mosquitoes divided by the number of sleepers in the rooms visited the night before the collection

larger numbers of mosquitoes and pool screen-based molecular techniques will need to be assessed.

The observation that An. pharaoensis and An. rufipes were more frequently biting humans and their identification as secondary vectors of W. bancrofti in West Africa [27], raises the possibility that transmission can be sustained by a number of vectors other than the most prevalent (An. gambiae complex). The rain pattern in 2012 (frequency and abundance) likely played a role in the increased vector density, as well as in the increase in An. pharaoensis and An. rufipes frequencies $[28,29]$. However, what is needed is an adequately designed prospective study of W. bancrofti transmission dynamics and vector control in this region of Mali. In addition, HLC was much more effective at collecting Anopheles than PSC; because of potential ethical issues related to HLC [30], better collection methods are needed.
With very low human infection and vector infectivity rates, there is no evidence that $W$. bancrofti transmission has re-emerged in the study villages in the present study $[5,12]$. Nevertheless, new entomological studies are needed to understand transmission dynamics in the context of post MDA surveillance. Mosquito vectors transmit W. bancrofti in two primary patterns, limitation and facilitation. Limitation is typically exhibited by Culex species and allows more efficient L3 development when microfilaraemia loads are low. Conversely, facilitation (usually exhibited by Anopheles species) leads to decreased numbers of developing L3 when microfilaraemia loads are low. Because limitation of An. gambiae (sensu stricto) has been observed in Ghana [31], it should also be assessed in other geographic locations (e.g. Mali) given the possibility of adaptation or specific mutation that can modify mosquito's transmission pattern [32]. From our previous studies, in the same area, WHO 
criteria were met but the mosquitoes were still infective (infectivity rate of $0.02 \%$ ) when the MDA was stopped [6]. Taking into account the entomological data and determining a threshold could be beneficial to be able to safely stop MDA in highly LF endemic areas.

Despite a dramatic and stable decrease in the prevalence of infection in the older age groups and in mosquitoes 5 years following the cessation of MDA in six villages previously highly endemic for LF, a significant increase in the prevalence of LF antigenemia as assessed by ICT occurred among 6-7 year-old children. Although the ICT prevalence in this age group met WHO criteria for restarting MDA ( $>$ 2\% ICT-positive) [5], the prevalence using the Og4C3 ELISA and Wb123 antibody ELISA were below the threshold. Furthermore, the observed prevalence increase within this group contrasted with the entomological data that showed an absence of LF transmission and the absence of microfilaraemia in all individuals tested.

\section{Conclusions}

Using a set of LF testing methods (ICT, Wb123, Og4C3 ELISA, and vector surveillance), we demonstrated differences among the various techniques considered important for post-MDA assessments. Our data suggest, nevertheless, that an integrated assessment strategy that combines serologic- and vector-based techniques may be useful in the assessment of transmission interruption following cessation of MDA in LF-endemic areas.

\section{Abbreviations \\ ABR: Annual biting rate; CFA: Circulating filarial antigen; \\ DNA: Deoxyribonucleic acid; GPELF: Global program to eliminate lymphatic filariasis; HLC: Human landing catch; ICT: Immunochromatographic card tests; IgG4: Immunoglobulins g4; LF: Lymphatic filariasis; MDA: Mass drug administration; NIAID: National Institute of Allergy and Infectious Diseases; $\mathrm{NIH}$ : National Institute for Health; POC: Point of care; PSC: Pyrethrum spray catch; RNA: Ribonucleic acid; RT-PCR: Reverse transcriptase polymerase chain reaction; SPSS: Statistical package for social sciences; TAS: Transmission assessment surveys; UNDP: United Nation Development Programme; WHO: World Health Organization}

\section{Acknowledgements}

The authors are indebted to the study participants and the villages' leaders for their collaboration. The Sikasso health and administration authorities as well as the Kolokoba rural commune deserve a special thank for their assistance.

\section{Funding}

This study was funded by the WHO/UNDP/World Bank Special Program for Tropical Diseases grant (ID A00583) to SFT and the Task Force for Global Health. This study was funded in part by the Division of Intramural Research, NIAID, NIH. The funding bodies did not play any role in the study design, data collection, analysis and interpretation, nor the decision to write the manuscript.

\section{Availability of data and materials}

The datasets generated and analysed during this study are presented in Tables 1, 2, 3 and 4. Additional information can be available from the authors upon reasonable request.

\section{Authors' contributions}

YIC, SFT, YTT, DK designed and conceived the study; YIC, MS, MD, YTT, LKH, $\mathrm{KP}, \mathrm{SFT}, \mathrm{MB}, \mathrm{AK}, \mathrm{TBN}$ approved final version of the manuscript and helped with the analysis and drafting of the manuscript; SYC, HD, SK, AAD, SSD, LS, MEC, ID, MBS, BD collected and processed the samples and drafted the manuscript; YIC, BD, HD, ID, MBS, SK, SYC, HD, AAD managed the data, did the statistical analysis and helped to draft the manuscript. All authors read and approved the final manuscript.

\section{Competing interests}

The authors declare that they have no competing interests.

\section{Consent for publication}

Not applicable.

\section{Ethics approval and consent to participate}

The protocol and consent form were approved by the Ethical Committee of the Faculty of Medicine and Odontostomatology of Bamako, Mali (No. 01-51/FMOS). A local guide in the presence of a research team member explained the goals, procedures and risks of the study to the volunteers. All participants provided informed assent or consent before the blood collection. For volunteers $<18$ years of age, a parent or an adult tutor provided consent.

\section{Author details}

${ }^{1}$ Filariasis Unit, International Center of Excellence in Research, Faculty of Medicine and Odontostomatology, Point G, Bamako, Mali. ${ }^{2}$ National Lymphatic Filariasis Elimination Program, Bamako, Mali. ${ }^{3}$ Faculty of Medicine and Odontostomatology of Bamako, Bamako, Mali. ${ }^{4}$ Filarial Program Support Unit, Liverpool School of Tropical Medicine, Liverpool, UK. ${ }^{5}$ Department of Biomedical Sciences, Institute of Tropical Medicine, Antwerp, Belgium. ${ }^{6}$ Neglected Tropical Diseases Support Center, Task Force for Global Health, Decatur, GA, USA. ${ }^{7}$ Department of Vector Biology, Liverpool School of Tropical Medicine, Liverpool L3 5QA, UK. ${ }^{8}$ Laboratory of Parasitic Diseases, National Institute of Allergy and Infectious Diseases, National Institutes of Health, Bethesda, MD, USA.

Received: 9 May 2016 Accepted: 24 November 2016 Published online: 03 December 2016

References

1. Ramaiah KD, Ottesen EA. Progress and impact of 13 years of the global programme to eliminate lymphatic filariasis on reducing the burden of filarial disease. PLoS Negl Trop Dis. 2014;8:e3319.

2. WHO. Global programme to eliminate lymphatic filariasis: progress report, 2013. Wkly Epidemiol Rec. 2014;89:409-18.

3. Dembélé $M$, Bamani $S$, Dembélé $R$, Traoré $M O$, Goita $S$, Traoré $M N$, et al. Implementing preventive chemotherapy through an integrated national neglected tropical disease control program in Mali. PLoS Negl Trop Dis. 2012; doi: 10.1371/journal.pntd.0001574.

4. Coulibaly YI, Dembele B, Diallo AA, Kristensen S, Konate S, Dolo H, et al. Wuchereria bancrofti transmission pattern in southern Mali prior to and following the institution of mass drug administration. Parasit Vectors. 2013;6:247.

5. WHO. Lymphatic filariasis. Monitoring and epidemiological assessment of mass drug administration. Geneva: World Health Organization; 2011.

6. Coulibaly YI, Dembele B, Diallo AA, Konate S, Dolo H, Coulibaly SY, et al. The impact of six annual rounds of mass drug administration on Wuchereria bancrofti infections in humans and in mosquitoes in Mali. Am J Trop Med Hyg. 2015;93:356-60.

7. Laney SJ, Ramzy RM, Helmy HH, Farid HA, Ashour AA, Weil GJ, et al. Detection of Wuchereria bancrofti $\mathrm{L} 3$ larvae in mosquitoes: a reverse transcriptase PCR assay evaluating infection and infectivity. PLoS Negl Trop Dis. 2010;4:e602

8. Steel C, Golden A, Kubofcik J, LaRue N, de Los Santos T, Domingo GJ, et al. Rapid Wuchereria bancrofti-specific antigen Wb123-based lgG4 immunoassays as tools for surveillance following mass drug administration programs on lymphatic filariasis. Clin Vaccine Immunol. 2013;20:1155-61.

9. Coulibaly YI, Dao S, Traore AK, Diallo A, Sacko M, Traore SF. Presence and risk of transmission of Wuchereria bancrofti is a reality in rural Mali: the case of the town of Bariambani in the Cirle of Kati. Mali Med. 2006;21:12-7 [In French]. 
10. Detinova TS, Gillies MT. Observations on the determination of the age composition and epidemiological importance of populations of Anopheles gambiae Giles and Anopheles funestus Giles in Tanganyika. Bull World Health Organ. 1964;30:23-8.

11. Goodman DS, Orelus JN, Roberts JM, Lammie PJ, Streit TG. PCR and mosquito dissection as tools to monitor filarial infection levels following mass treatment. Filaria J. 2003;2:11.

12. WHO. Global Programme to eliminate lymphatic filariasis: practical entomology. Geneva: World Health Org; 2013. http://apps.who.int/iris/ bitstream/10665/87989/1/9789241505642_eng.pdf. Accessed 15 Mar 2015

13. Walsh JF, Davies JB, Le Berre R, Grams R. Standardization of criteria for assessing the effect of Simulium control in onchocerciasis control programmes. Trans R Soc Trop Med Hyg. 1978;72:675-6.

14. Dorkenoo AM, Sodahlon YK, Bronzan RN, Yakpa K, Sossou E, Ouro-Medeli A, et al. Lymphatic filariasis transmission assessment survey in schools three years after stopping mass drug treatment with albendazole and ivermectin in the 7 endemic districts in Togo. Bull Soc Pathol Exot. 2015;108:181-7.

15. Wanji S, Amvongo-Adjia N, Koudou B, Njouendou AJ, Chounna Ndongmo PW, Kengne-Ouafo JA, et al. Cross-reactivity of filariais ICT cards in areas of contrasting endemicity of Loa loa and Mansonella perstans in Cameroon: Implications for shrinking of the lymphatic filariasis map in the central African region. PLoS Negl Trop Dis. 2015;9:1-20.

16. Bakajika DK, Nigo MM, Lotsima JP, Masikini GA, Fischer K, Lloyd MM, et al. Filarial antigenemia and Loa loa night blood microfilaremia in an area without bancroftian filariasis in the democratic republic of Congo. Am J Trop Med Hyg. 2014;91:1142-8.

17. Keiser PB, Coulibaly YI, Keita F, Traore D, Diallo A, Diallo DA, et al. Clinical characteristics of post-treatment reactions to ivermectin/albendazole for Wuchereria bancrofti in a region co-endemic for Mansonella perstans. Am J Trop Med Hyg. 2003;69:331-5.

18. Richards FO, Eigege A, Miri ES, Kal A, Umaru J, Pam D, et al. Epidemiological and entomological evaluations after six years or more of mass drug administration for lymphatic filariasis elimination in Nigeria. PLoS Negl Trop Dis. 2011;5:e1346.

19. Ramaiah KD, Vanamail P. Surveillance of lymphatic filariasis after stopping ten years of mass drug administration in rural communities in south India. Trans R Soc Trop Med Hyg. 2013;107:293-300.

20. Kia EB, Sharifdini M, Hajjaran H, Shahbazi AE, Sayyad TZ. Imported lymphatic filariasis in an Indian immigrant to Iran. Iran J Parasitol. 2014;9:145-8.

21. Harnett W, Bradley JE, Garate T. Molecular and immunodiagnosis of human filarial nematode infections. Parasitology. 1998;117(Suppl):S59-71.

22. Weil GJ, Ramzy RM. Diagnostic tools for filariasis elimination programs. Trends Parasitol. 2007;23:78-82.

23. Kubofcik J, Fink DL, Nutman TB. Identification of Wb123 as an early and specific marker of Wuchereria bancrofti infection. PLoS Negl Trop Dis. 2012;6: e1930.

24. Golden A, Steel C, Yokobe L, Jackson E, Barney R, Kubofcik J, et al. Extended result reading window in lateral flow tests detecting exposure to Onchocerca volvulus: a new technology to improve epidemiological surveillance tools. PLoS One. 2013;8:e69231.

25. Lovato R, Guevara A, Guderian R, Proaño R, Unnasch T, Criollo H, et al. Interruption of infection transmission in the onchocerciasis focus of Ecuador leading to the cessation of ivermectin distribution. PLoS Negl Trop Dis. 2014;8:e2821.

26. Lamberton $\mathrm{P}$, Cheke RA, Walker M, Winskill P, Osei-Atweneboana MY, Tirados I, et al. Onchocerciasis transmission in Ghana: biting and parous rates of host-seeking sibling species of the Simulium damnosum complex. Parasit Vectors. 2014;7:511.

27. Brengues J, Subra R, Mouchet J, Nelson GS. [Transmission of Wuchereria bancrofti Cobbold in West Africa. Preliminary study of a focus in the savanna of north Guinea]. Bull World Health Organ. 1968;38(4):595-608. French.

28. Talla C, Diallo D, Dia I, Ba Y, Ndione JA, Sall AA, et al. Statistical modelling of the abundance of vectors of West African Rift Valley fever in Barkédji, Senegal. PLoS One. 2014;9:e114047.

29. Ngom E, Faye N, Talla C, Ndiaye E, Ndione JA, Faye O, et al. Anopheles arabiensis seasonal densities and infection rates in relation to landscape classes and climatic parameters in a Sahelian area of Senegal. BMC Infect Dis. 2014;14:711.

30. Govella NJ, Moore JD, Killeen GF. An exposure-free tool for monitoring adult malaria mosquito populations. Am J Trop Med Hyg. 2010;83:596-600.
31. Amuzu H, Wilson MD, Boakye DA. Studies of Anopheles gambiae s.l. (Diptera: Culicidae) exhibiting different vectorial capacities in lymphatic filariasis transmission in the Gomoa district, Ghana. Parasit Vectors. 2010;3:85.

32. Southgate BA, Bryan JH. Factors affecting transmission of Wuchereria bancrofti by anopheline mosquitoes. 4. Facilitation, limitation, proportionality and their epidemiological significance. Trans R Soc Trop Med Hyg. 1992;86:523-30.

\section{Submit your next manuscript to BioMed Central and we will help you at every step:}

- We accept pre-submission inquiries

- Our selector tool helps you to find the most relevant journal

- We provide round the clock customer support

- Convenient online submission

- Thorough peer review

- Inclusion in PubMed and all major indexing services

- Maximum visibility for your research

Submit your manuscript at www.biomedcentral.com/submit 